\title{
DISCRIMINATION AND CHARACTERIZATION OF PROMINENT DESERTIC VEGETATIONS USING HYPERSPECTRAL IMAGING DATA
}

\author{
S.L. Borana *, S.K. Yadav and R.T. Paturkar \\ Remote Sensing Group, DL, Jodhpur, Rajasthan (INDIA) \\ *sohanlb@gmail.com
}

Keywords: Hyperspectral Imaging, Discrimination, ENVI, Vegetation Index.

\begin{abstract}
ABSTARCT
Imaging Hyperspectral data are advent as potential solutions in modeling, discrimination and mapping of vegetation species. Hyperspectral remote sensing provides valuable information about vegetation type, leaf area index, chlorophyll, and leaf nutrient concentration. Estimation of these vegetation parameters has been made possible by calculating various vegetation indices (VIs), usually by ratioing, differencing, ratioing differences and combinations of suitable spectral band. This paper presents a ground-based hyperspectral imaging system for characterizing vegetation spectral features. In this study, a ground-based hyperspectral imaging data (AISA VNIR 400-960 nm, Spectral Resolution @ 2.5nm) was used for spectral vegetation discrimination and characterization of natural desertic tree species. This study assessed the utility of hyperspectral imagery of 240 narrow bands in discrimination and classification of desert tree species in Jodhpur region using ENVI software. Vegetation indices derived from hyperspectral images used in the Analysis for tree species classification discrimination study. Prominent occurring two desertic tree species, viz., Neem and Babul in Jodhpur region could be effectively discriminated. Study demonstrated the potential utility of narrow spectral bands of Hyperspectral Imaging data in discriminating vegetation species in a desertic terrain.
\end{abstract}

\subsection{INTRODUCTION}

Remote sensing is the method of acquire data about the Earth's surface without physical contact with the object. The most significant advancement in the remote sensing has been the development of hyperspectral sensors and software to analyze the resulting image data. From last decade hyperspectral image analysis has developed in the most powerful and fastest growing technologies in the field of remote sensing.

Hyperspectral images are spectrally over determined, which means that they provide sufficiency spectral information to identify and distinguish spectrally distinct materials. Hyperspectral imagery offers the potential for accurate and complete information extraction. The ability of hyperspectral data to improve the characterization, discrimination, modeling, and mapping of vegetation, when compared with broadband multispectral remote sensing, is well known [8]. Hyperspectral data acquired from field based Aisa hyperspectral system in the 400-960 nm spectrum, provides important information about vegetation type, leaf area index, chlorophyll, and leaf nutrient concentration which are used to identify ecosystem and vegetation growth.

\subsection{STUDY AREA}

The Thar desert in Rajasthan is bound by North latitude of $24^{\circ} 30^{\prime}$ and $30^{\circ} 0$ and East Longitude of $60^{\circ} 30^{\prime}$ and $76^{\circ} 0$. Average elevation of this undulating desertic terrain varies from $200 \mathrm{~m}$ to $300 \mathrm{~m}$ MSL. The study area is located in arid part of western Rajasthan with latitude of $26^{\circ} 8^{\prime} 30^{\prime \prime}$ to $26^{\circ} 23^{\prime} 28^{\prime \prime}$ North and longitude of $72^{\circ} 52^{\prime} 46^{\prime \prime}$ to $73^{\circ} 10^{\prime} 52^{\prime \prime}$ East (Fig.1) and total coverage area of $80 \mathrm{sq}$. $\mathrm{km}$. Its general topography is characterized by the hills located in the North and North-west and altitude of $241 \mathrm{~m}$ above Mean Sea Level. The climate is characterized as arid to semiarid with long hot summer, with low rainfall and sparse vegetation The common landforms are hill slopes, rocky/gravelly pediments, flat buried pediment, alluvial plains, palaeo channels, hammada and number of saline depressions or playa.

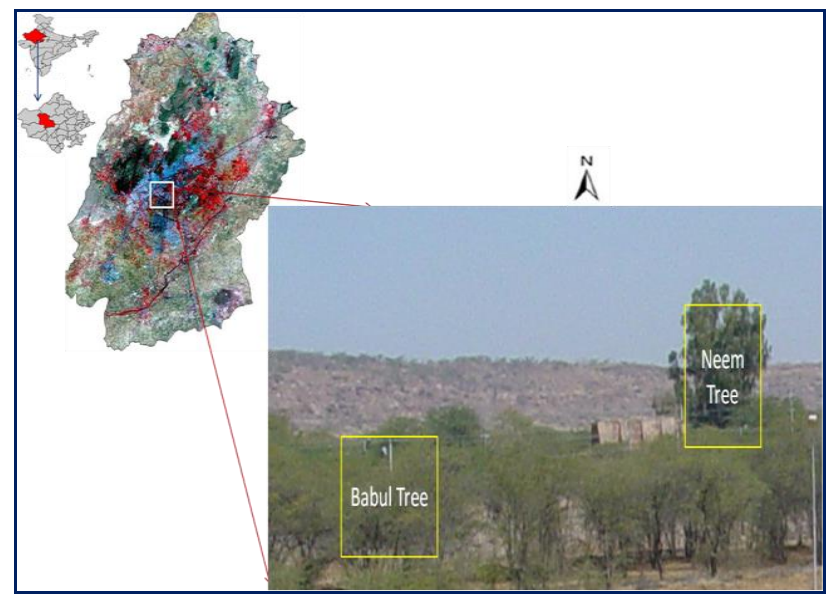

Fig. 1. Map of the Study Area.

\subsection{DATA USED AND METHODOLOGY}

The aim of this paper is to measurement and analysis of Hyperspectral data and spectral signatures of the prominent vegetation in the study area. False Colour Images of Hyperspectral data is used to image processing for estimation of vegetation index and signatures. ENVI software are used for data interpretation, subseting and analysis. Prominent vegetation species are shown in Table-1. The detailed methodology flow chart is given in Fig.2.

Table-1 Vegetation Species for Hyperspectral data collection

\begin{tabular}{|c|c|c|}
\hline S.No. & $\begin{array}{l}\text { Species Local } \\
\text { Name }\end{array}$ & Scientific Name \\
\hline 1 & Neem & Azadirachta indica \\
\hline 2 & Babul & Acacia nilotica \\
\hline
\end{tabular}




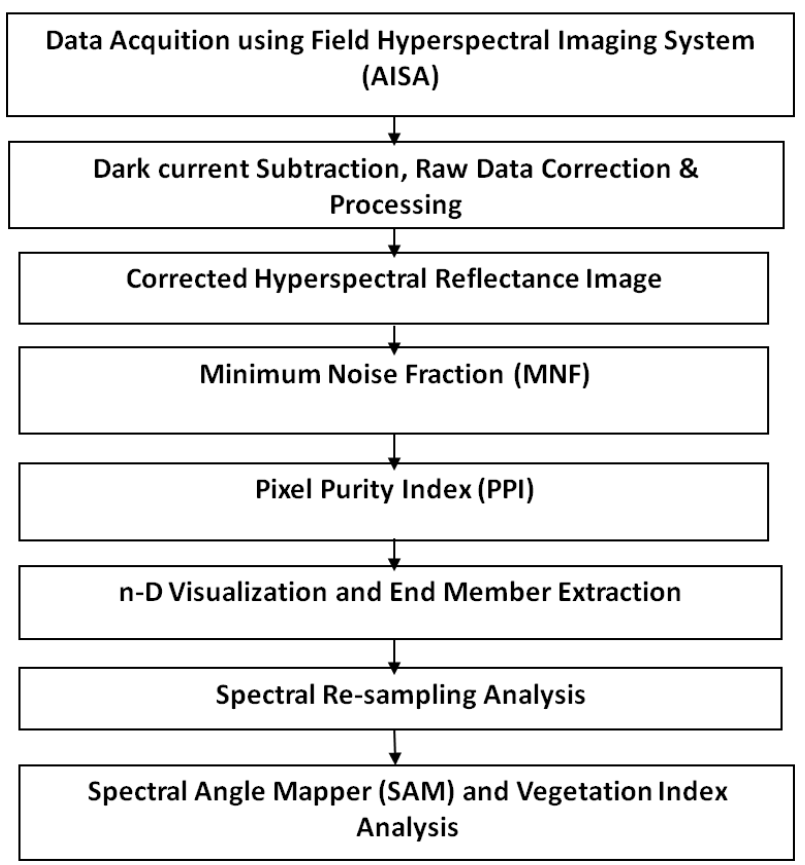

Fig.2. Methodology Flow Chart

\subsection{Hyperspectral Imaging System:}

Hyper-spectral imaging system covers the VIS-NIR region of electromagnetic spectrum. The data that the system generates are hyper-spectral Images of the scene in its field of view. The data consists of 240 images of the scene. Each image pertains to a specific electromagnetic band of about 2.5 nanometer. All the 240 images put together cover the visible and near infrared region $(400 \mathrm{~nm}$ thru' $960 \mathrm{~nm})$. It has separate input for measuring incident solar irradiance through Fiber Optic Down welling Irradiance Sensor and 1mrad. FOV: 300 X 600 (Spatial resolution of $1 \mathrm{~cm}$ from height of $10 \mathrm{~m}$ ). The data collected from the system needs further analysis. The analysis is aimed at understanding the implications of the measurements carried out. Spectral analysis gives the insight into the blending of the various objects with their expected surrounding in terms of reflection at different wavelengths and spatial analysis gives us the overall insight of merging of the object and its parts thereof with the background.

ENVI software 3D Cube tool is used to generate a colorcomposite data cube image with the spectral slice of the top row and far-right column in a perspective view. The spectral pieces are stretched and a selected color table is applied. Two dimensions of the image-cube are the spatial dimensions of the scene, and the third dimension is the wavelength (Fig.3). In this way, each spatial pixel in the image has an associated reflectance spectrum (Cucci, Costanza; Delaney, John K; Picollo, Marcello, 2016).

\subsection{Processing of Hyperspectral Data:}

Hyperspectral data is a superset of data with hundreds of bands. It is very voluminous. For a given application, only a small subset of the hyperspectral data is generally used. All the other bands are redundant as far as the particular application is concerned. Identification of such useful subset is the initial step in the hyperspectral data analysis. In this work, Hyperspectral data of the prominent vegetation species were acquired from height of 2 metre using a Tripod mounted Hyperspectral Imaging System. Fig.4(a,b) shows the false color composite (FCC) and True color composite (TCC) images of the area of interest, synthesized from the hyperspectral data cube. At 2 metre height, the system provides data with spatial resolution of $2 \mathrm{~mm}$.

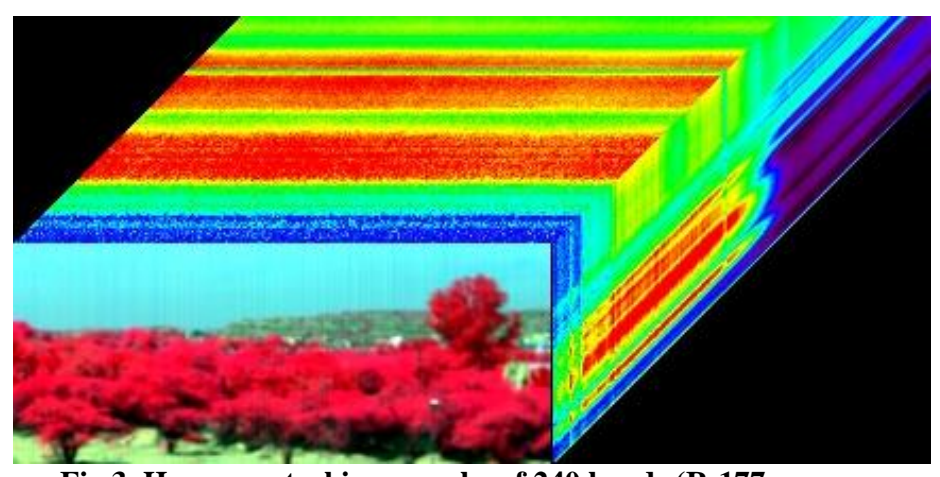

Fig.3. Hyperspectral image cube of 240 bands (R:177, G:119, B:59).

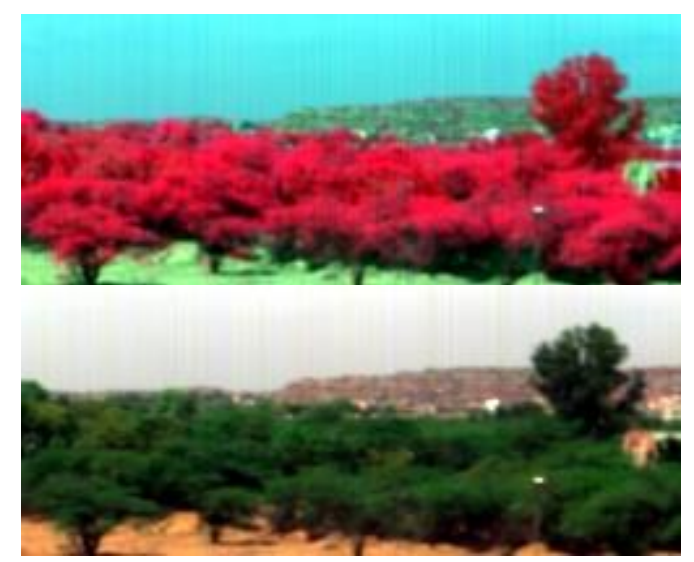

Fig.4. (a) FCC Composite Image (b) TCC Composite Image

\subsection{Minimum Noise Transform}

The data cube was subjected to Forward Minimum Noise Fraction (MNF) Transform to find out the dimensionality of the data. The Minimum Noise Fraction (MNF) transform determines the inherent dimensionality of image data and consequently segregates the noise in the data for improved subsequent processing (Boardman and Kruse, 1994). It essentially gives us an idea that for a given image and sensor attributes, how many bands of data will have useful information. The result is a set of images, in MNF domain, with as many bands as in the original data cube, with decreasing information content. Additionally, from the plot on the Eigen value of these bands, we can find out the useful number of bands. Bands with Eigen values more than one will have information whereas remaining bands will be dominantly noise. The data dimensionality indicates the number of intrinsic endmembers in the data set. The eigenvalue closer to 1 indicates more noise in the transformed band. From Fig.5-7, we can derive that about 10 bands of data will be useful for our application. In an attempt to remove/reduce noise component, Inverse MNF is performed using only the first 10 bands. This results in 240 bands of noise-reduced data in original image domain. These images are used in further analysis. 


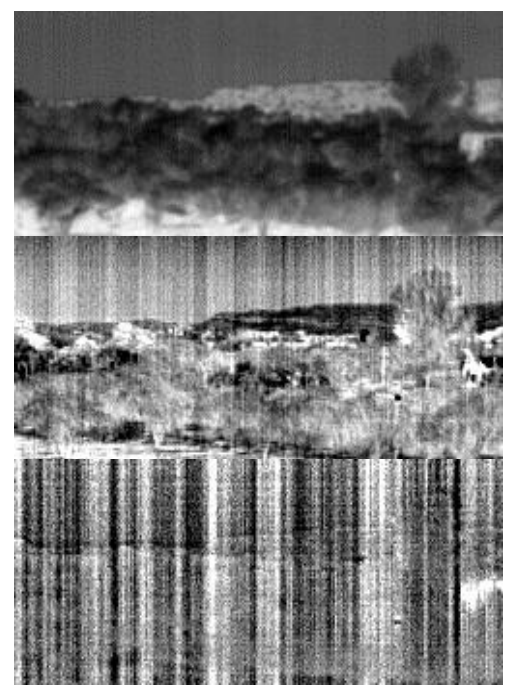

Fig. 6: MNF transform bands (a) MNF-Band2 (b) MNFBand-7 and (c) MNF-Band-10.

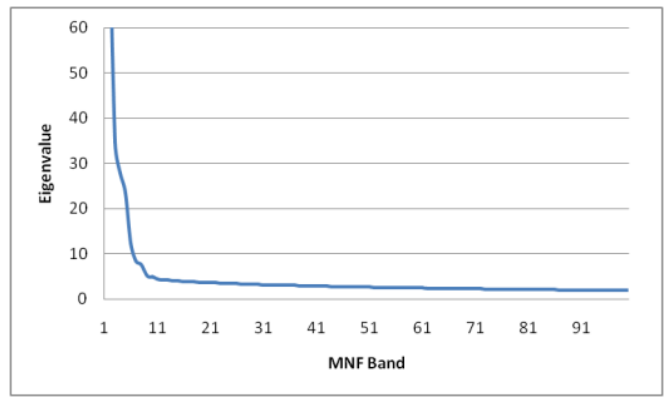

Fig.6. MNF plot shows the eigenvalue 5 corresponds to the 10 first MNF bands.

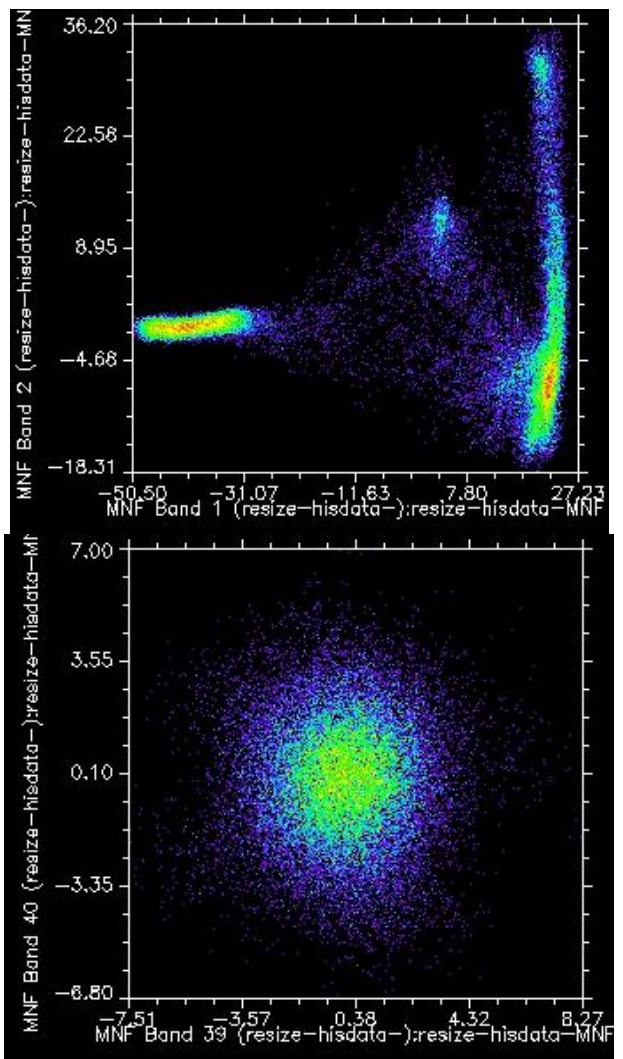

Fig.7. 2-D ScatterPlot of MNF EignValue (a) MNF bands $1 \& 2$ (b) MNF bands 39\&40

\subsection{Pixel Purity Index}

Pixel Purity Index (PPI) analysis is used to find out the pure pixels in the MNF transformed data. For mixed pixels it gives a measure of their purity. ENVI software used to create the PPI by repeatedly projecting $n$-dimensional scatter plots onto a random unit vector. PPI is highly computationally intensive process, which involves thousands of iterations. Fig. 8 shows the progress of the PPI process by plotting the iteration number versus number pixels verified. After 10000 iterations, 15425 pixels were found to be the spectrally purest. There was no need for further iterations as the PPI plot behaviour at the higher iterations was flat, indicating slim possibilities of finding further pixel designated as purest. The resulting Pixel Purity image is shown in Fig.9, where the brighter pixels represent higher purity.

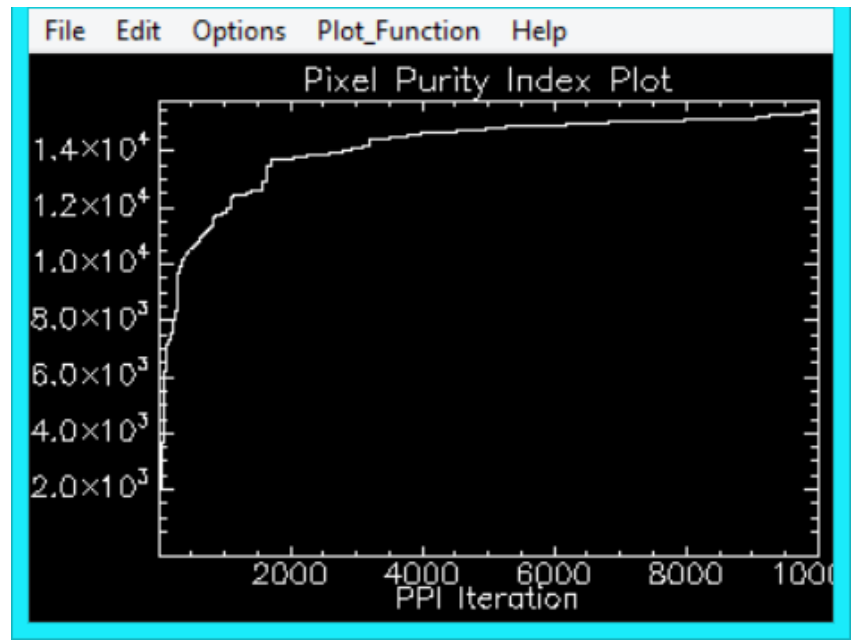

Fig.8: The performance of PPI and selected pixels as purest pixels versus iteration.

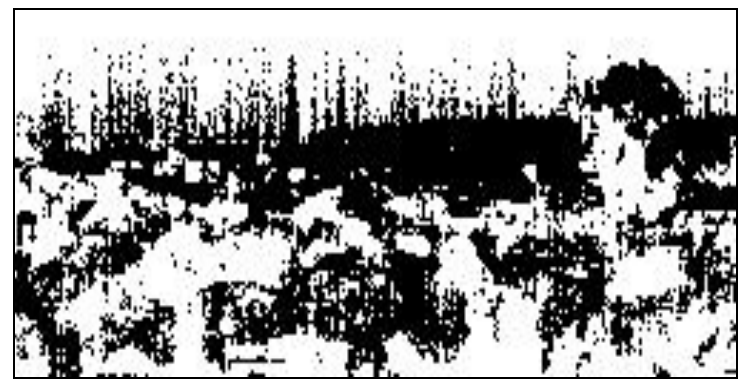

Fig.9: Pixel Purity Index Image of the Hyperspectral Data.

\subsection{The $n$-Dimensional Visualiser}

Pure pixels were used for finding endmembers in the image in n-Dimensional Visualiser tool. This was achieved through locating and automated clustering retrieved 10 endmembers as shown in Fig. 10. 


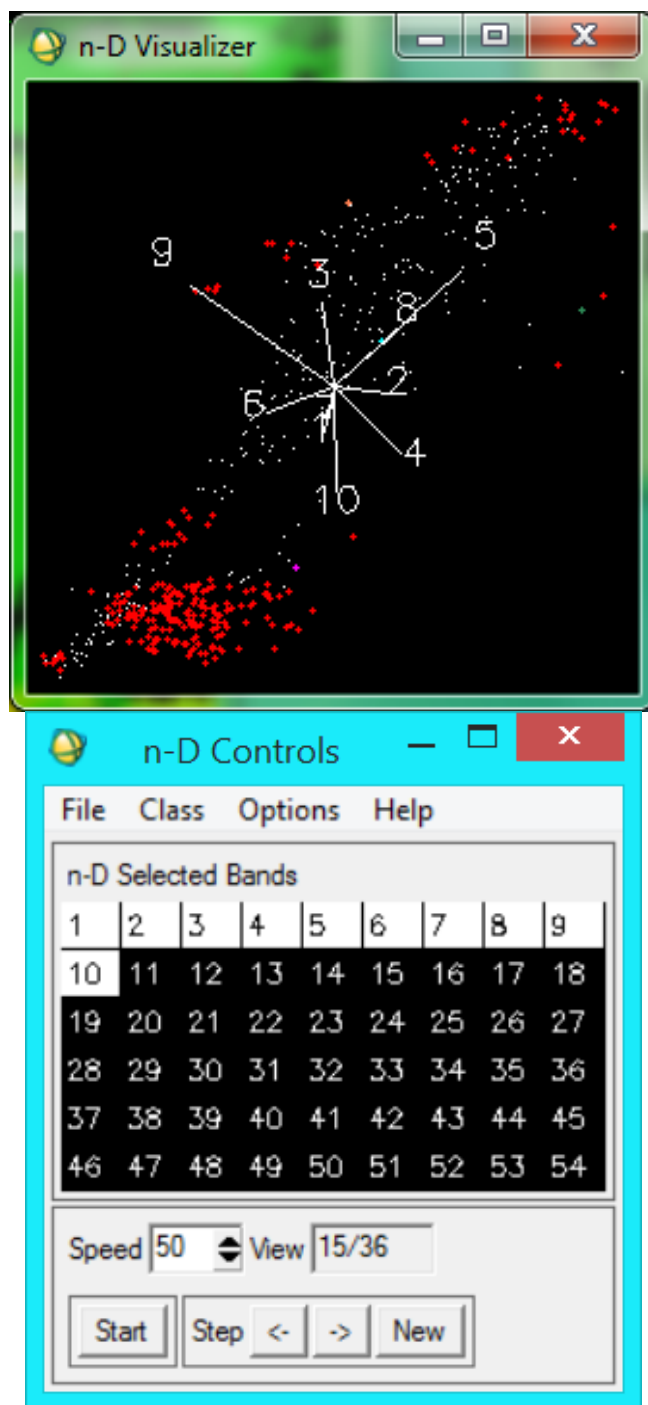

Fig.10. Display of the clustering of purest pixels in the $n \mathrm{D}$ visualiser.

\subsection{RESULTS \& DISCUSSION}

\subsection{Spectral Angle Mapper:}

SAM is a physically based spectral classifier which uses a $\mathrm{n}$ Dimentional angle to classify the pixels to reference spectrum (Kruse, Lefkoff et al. 1993). The algorithm detect the spectral similarity in spectrums by computing the angle between the reference and observed spectrum and use them as vectors with dimensions equal to the number of bands. The smaller the angular separation, the closer the match between the observed and reference spectrum. Pixels further away than the specified highest angle threshold in radians are not classified ( Helmi Zulhaidi Mohd Shafri at el, 2007). Consequently, it will match each spectral pixel signature in the of the study area image to the selected endmember vegetation spectral signature. The result of SAM classifier algorithm is shown in Fig.11, where the desse vegetation is represented by the dark green color, spare vegetation as light green colour, fellow land as yellow and other area as black colour.

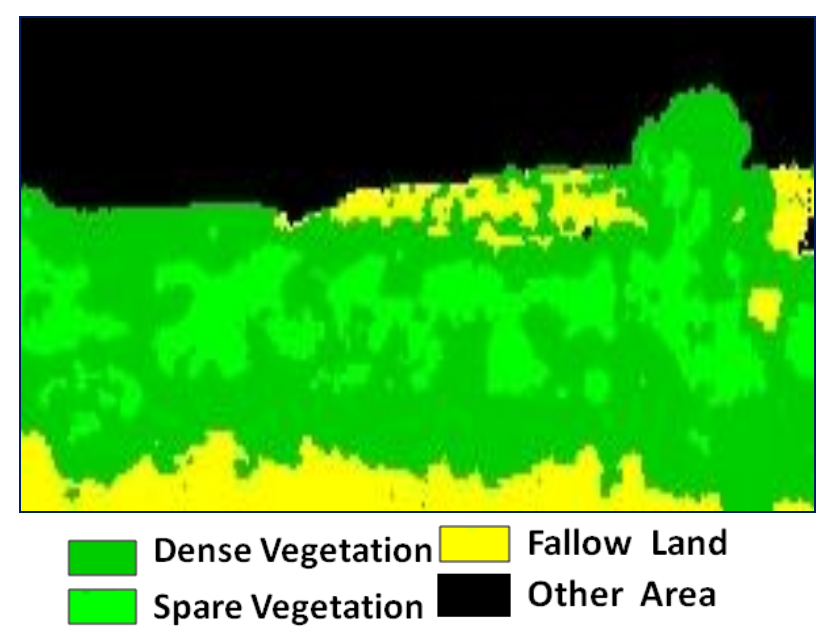

Fig.11. SAM Classifier of the Study Area

\subsection{Spectral Data Analysis and discrimnation:}

In the next step, for each of the vegetation types spectral signature is derived from a set of high purity pixels. The spectral signatures derived for the vegetation types is given in Fig.12-14. The wavelength region between 400 and $900 \mathrm{~nm}$ provides good separability among the signatures. While almost all the sensors in space platform are of broad band type with spectral bandwidth of about 70 nanometre, it is worthwhile to check the suitability of such broad band data for the envisaged application of vegetation mapping.

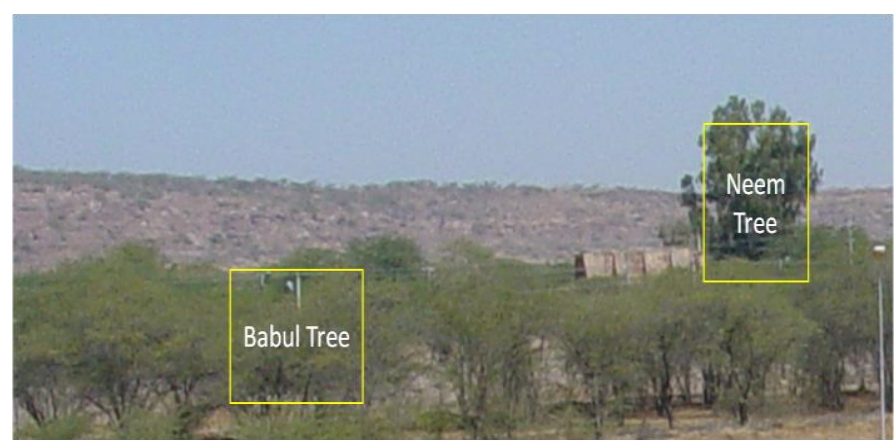

Fig.12. Field Photo of Data Acquition Sites of Babul and Neem Trees

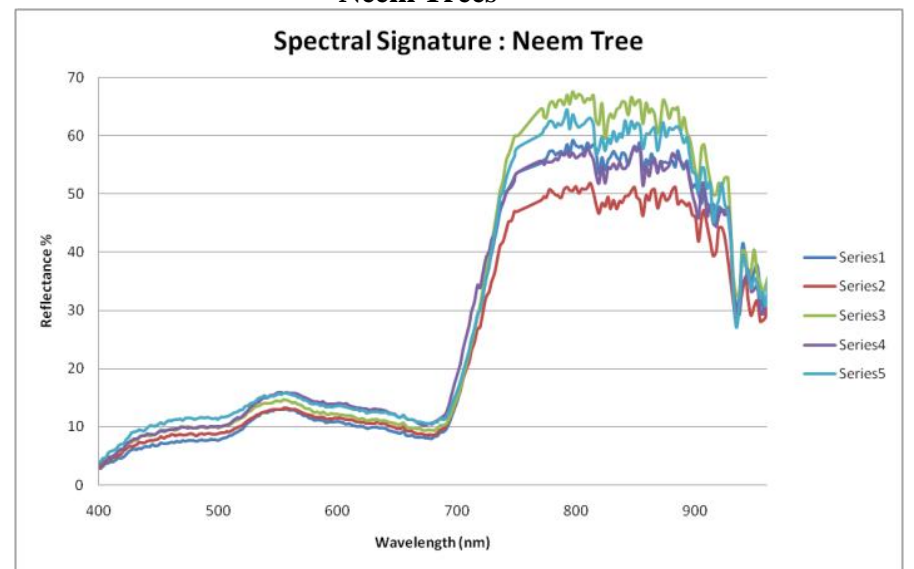

Fig. 13. Spectral Signature of Neem Trees . 


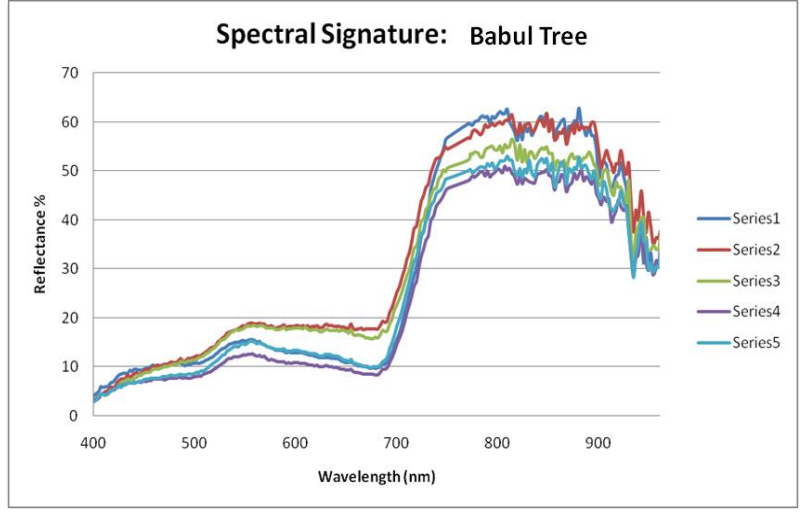

Fig.14. Spectral Signature of Babul Trees.

\subsection{Vegetation Indices Analysis:}

The Normalized Difference Vegetation Index (NDVI)

The most widely used broadband greenness Vegetation Index is the NDVI (Rouse et al., 1973). NDVI measures the differences between red and NIR centres for vegetation studies (Jackson, Slater and Pinter, 1983; Ma et al., 2007; Sellers, 1985; Tucker, 1979). NDVI is very useful in comparative analysis as an indicator to productivity and chlorophyll canopy content (Merton, 1998). The value of this index varies from -1 to +1 . the common range for the green vegetation is 0.2 to 0.8 (Fig.15a). NDVI is defined by following Equation.

$$
\text { NDVI }=(\text { NIR }- \text { RED }) /(\text { NIR }+ \text { RED })
$$

NIR=reflectance at the NIR range of the wavelength $\mathrm{RED}=$ reflectance at the red range of the wavelength

\section{Simple Ratio Index (NIR/Red):}

This index is related to greenness Image and is described as the ratio of light that is scattered in the NIR range to that which is absorbed in the red range(Fig.15b). The value range is from 0 to around 30 , where healthy vegetation falls between values of 2 to 8 (Chen JM, 1996).

\section{Enhanced Vegetation Index (EVI)}

The EVI was developed to improve the NDVI by optimizing the vegetation signal in the study area by using the blue reflectance to correct for soil background signals and reduce atmospheric influences including aerosol scattering (Fig.15c). EVI is defined by following Equation.

\section{EVI = (2.5) $\times($ NIR - RED $) /($ NIR - 6 RED - 7.5BLUE + 1$)$}

The value of this index ranges from -1 to +1 . The common range for green vegetation is 0.2 to 0.8 (Liu and Huete, 1995).

\section{Water band index (WBI)}

The WBI measure the reflectance that is sensitive to changes in water canopy content. As the water content of canopies vegetation increases, the strength of absorption around $970 \mathrm{~nm}$ increases to that of $900 \mathrm{~nm}$ (Peñuelas et al. 1993). WBI application includes canopy stress analysis, productivity prediction, cropland management, and studies of ecosystem. The common range of values for green vegetation is 0.8 to 1.2 (Fig.15d).

$$
\mathrm{WBI}=900 \mathrm{~nm} / 970 \mathrm{~nm}
$$
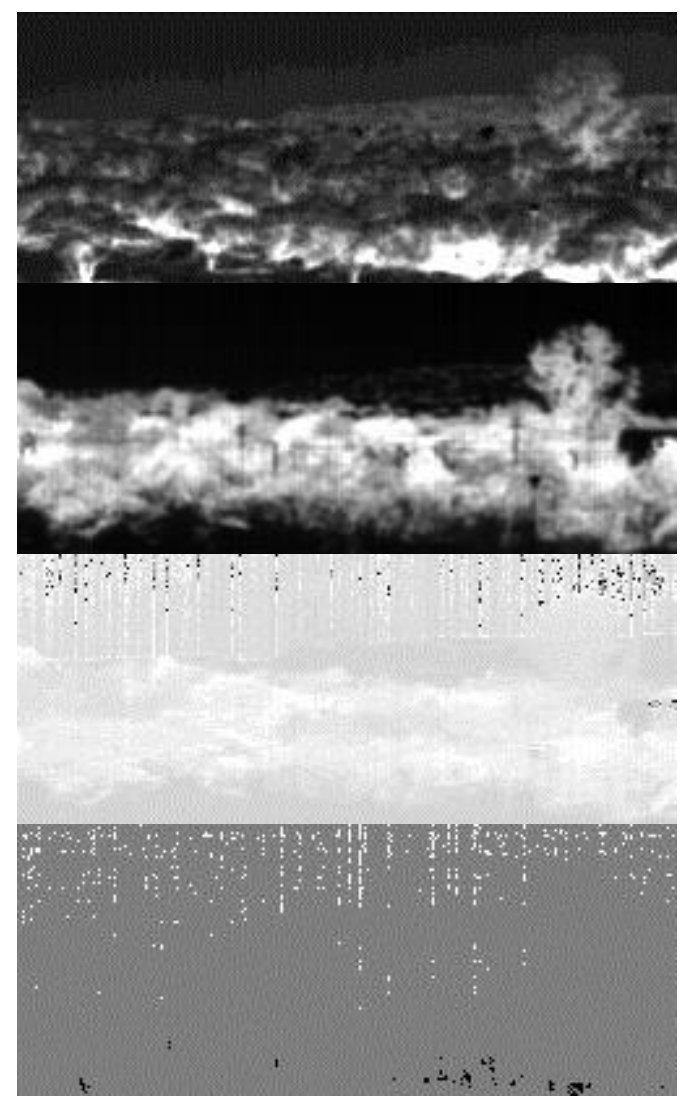

Fig.15. (a) NDVI Image (b) NIR/Red Image (c) EVI Image (d) Water Band Index

\subsection{CONCLUSIONS}

The use of Hyperspectral data Proved to be useful in discrimination the spatial distribution of the identified vegetation species. The above study also highlights the importance of HIS spectral signatures vegetation sample for discrimination mapping. Hyperspectral vegetation indices were identified for the study of prominent vegetation species discrimination. These results are further compared to field measurements and subsequent Hyperspectral analysis for validate the mapping accuracy.

\section{ACKNOWLEDGEMENT:}

The authors are thankful to the Director DL, Jodhpur, Rajasthan, for his help and encouragement during the study. The authors are also thankful to Head RS Group for his critical suggestions and encouragement.

\section{REFERENCES}

Saharan, M. A.; Vyas, N.; Borana, S. L.; Yadav, S. K.,Classification and Assessment of the Land Use - Land Cover Changes in Jodhpur City Using Remote Sensing Technologies, International Archives of the Photogrammetry, Remote Sensing \& Spatial Information Sciences . 11/20/2018, Vol. XLII-5, p767-771. 5p.

R. N. Sahoo1, S. S. Ray and K. R. Manjunath, Hyperspectral remote sensing of agriculture, Current Science, Vol. 108, NO. 5, 10 MARCH 2015. 
Thenkabail, P. S., Optimal hyperspectral narrow bands for discriminating agricultural crops. Remote Sensing Rev., 2002, 20, pp. 257-291.

Thenkabail, P. S., Enclona, E. A., Ashton, M. S. and Van Der Meer, B., Accuracy assessments of hyperspectral waveband performance for vegetation analysis applications. Remote Sensing Environ., 2004, 91(3-4), pp. 354-376.

Thenkabail, P. S., Smith, R. B. and Pauw, E. D., Hyperspectral vegetation indices and their relationships with agricultural crop characteristics. Remote Sensing Environ., 2000, pp. 71, 158182 .

Liu H.Q., Huete A.R. A feedback based modification of the NDV I to minimize canopy background and atmospheric noise. IEEE Transactions on Geoscience and Remote Sensing. 1995;33: pp. 457-465.

Jordan CF (1969) Derivation of leaf area index from quality of light on the forest floor. Ecology 50: 663-666.

Brown LJ, Chen JM, Leblanc SG, Cihlar J (2000) A shortwave infrared correction to the simple ratio: an image and model analysis. Remote Sensing of Environment 71: 16-25.

Chen JM (1996) Evaluation of vegetation indices and a modified simple ratio for boreal applications. Canadian Journal of Remote Sensing 22: 229-242.
Peg Shippert, Introduction to Hyperspectral Image Analysis, Research Systems, Inc, https://spacejournal.ohio.edu/pdf/shippert.pdf.

Sahar A. El_Rahman, Performance of Spectral Angle Mapper and Parallelepiped Classifiers in Agriculture Hyperspectral Image, (IJACSA) International Journal of Advanced Computer Science and Applications, Vol. 7, No. 5, 2016.

ENVI, "ENVI Reference Guide", ENVI Version 4.7, Copyright (C) ITT Visual Information Solutions All Rights Reserved, August, 2009.

Dongha Lee and Sunhui Sim, "The Application of Hyperspectral Sensing Data for Seabed Classification in the Coastal Area of Korea”, International Electronic Conference on Sensors and application, June2014. www.mdpi.com/journal/sensors.

Hongyan Zhang, Han Zhai, Liangpei Zhang, Pingxiang Li, Spectral-Spatial Sparse Subspace Clustering for Hyperspectral Remote Sensing Images, IEEE Transactions on geoscience and remote sensing, vol. 54, no. 6, June 2016.

Gary A. Shaw and Hsiao-hua K. Burke, Spectral Imaging for Remote Sensing, VOLUME 14, NUMBER 1, 2003 Lincoln Laboratory Journal.

Cocks, R.Jensen, A.Stewart, I.Wilson, T.Sheilds, 1998. The HyMap Airborne Hyperspectral Sensor: The System, Calibration and Performance. (Paper presented at 1rst EARSEL Workshop on Imaging Spectroscopy, Zurich, October. 